\title{
Concave Cubic Pt-Sm Alloy Nanocrystals with High-Index Facets and Enhanced Electrocatalytic Ethanol Oxidation
}

Lu Wei, ${ }^{\dagger}$ Yu-Jie Mao, ${ }^{\dagger}$ Feng Liu, ${ }^{\dagger}$ Tian Sheng, $,{ }^{*}, \ngtr$ Yong-Sheng Wei, ${ }^{\dagger}$ Jian-Wei Li, ${ }^{\dagger}$ You-Jun Fan,,${ }^{*}$ Xin-Sheng Zhao*,†

†School of Physics and Electronic Engineering, Jiangsu Normal University, Xuzhou, 221116, China ${ }^{\ddagger}$ College of Chemistry and Materials Science, Anhui Normal University, Wuhu, 241000, China

${ }^{\S}$ Guangxi Key Laboratory of Low Carbon Energy Materials, School of Chemistry and Pharmaceutical Sciences, Guangxi Normal University, Guilin 541004, China

*E-mail: xinshengzhao@jsnu.edu.cn (X-S.Z.).

*E-mail: tsheng@ahnu.edu.cn (T.S.).

*E-mail: youjunfan@mailbox.gxnu.edu.cn (Y.-J.F.). 


\section{SEM Characterization.}
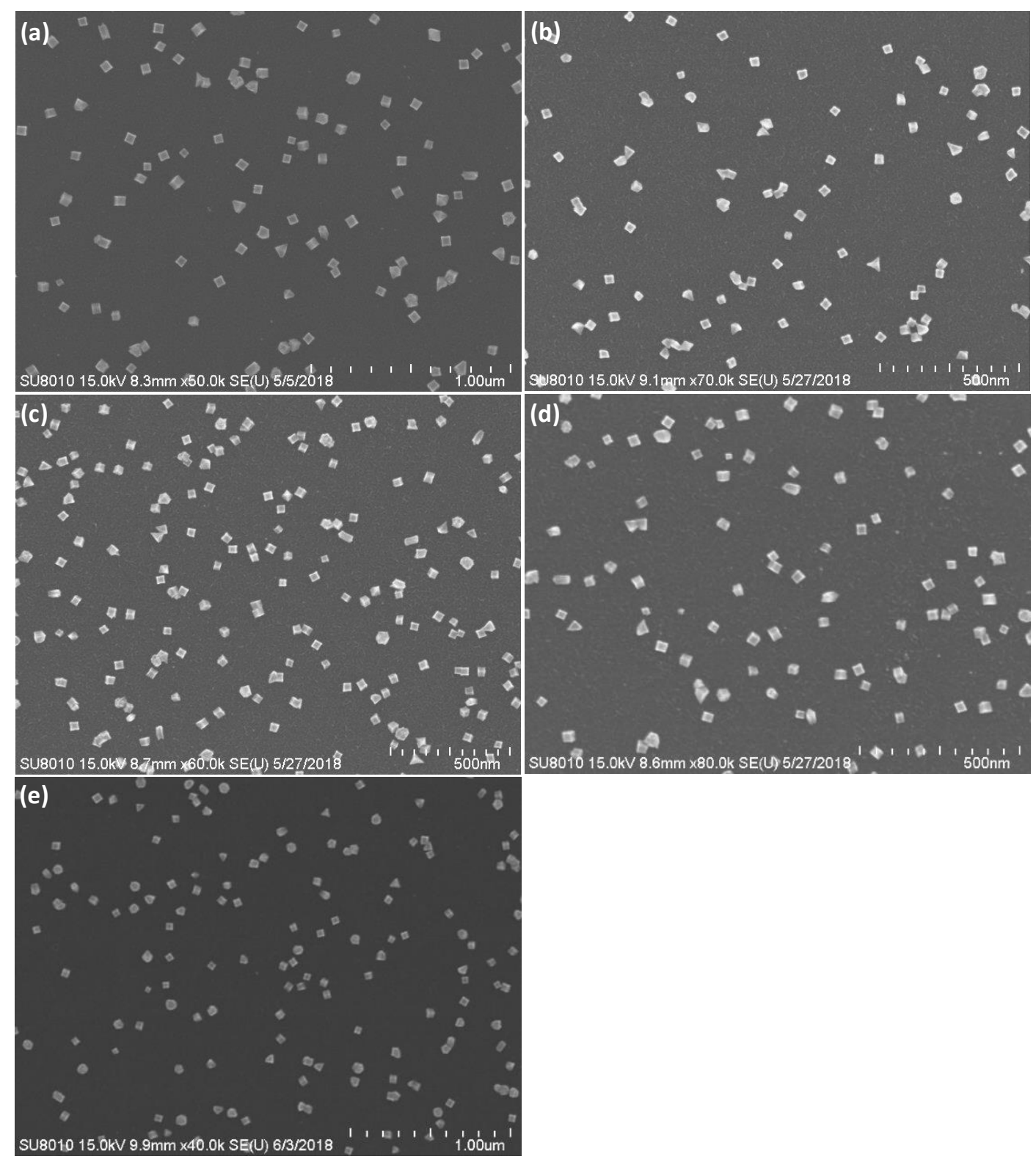

Figure S1. SEM images of electrodeposition obtained by using mixed precursors with Pt/Sm molar ratios of (a) 100:0, (b) 95:5, (c) 91:9, (d) 87:13 and (e) 83:17, respectively.

The control experiments with different molar ratios of $\mathrm{K}_{2} \mathrm{PtCl}_{6}$ and $\mathrm{Sm}\left(\mathrm{NO}_{3}\right)$ were carried out, as shown in Figure S1. It revealed that the concave cubic structures were obtained by using the mixed precursors with Pt/Sm molar ratios of 100:0, 95:5, 91:9 (ratio in the typical synthesis), 87:13 and 
83:17 (see Figure 2a, and Figure S1 in the Supporting Information).

Table S1. The calculated values for the angles of different high-index planes of Miller indices $\{h k 0\}$ with the $\{100\}$ plane.

\begin{tabular}{|l|l|l|l|l|l|}
\hline$\{h k 0\}$ & $\{320\}$ & $\{210\}$ & $\{310\}$ & $\{410\}$ & $\{510\}$ \\
\hline$\theta /^{\circ}$ & 33.69 & 26.56 & 18.43 & 14.03 & 11.31 \\
\hline
\end{tabular}

\section{EDX Spectrum}

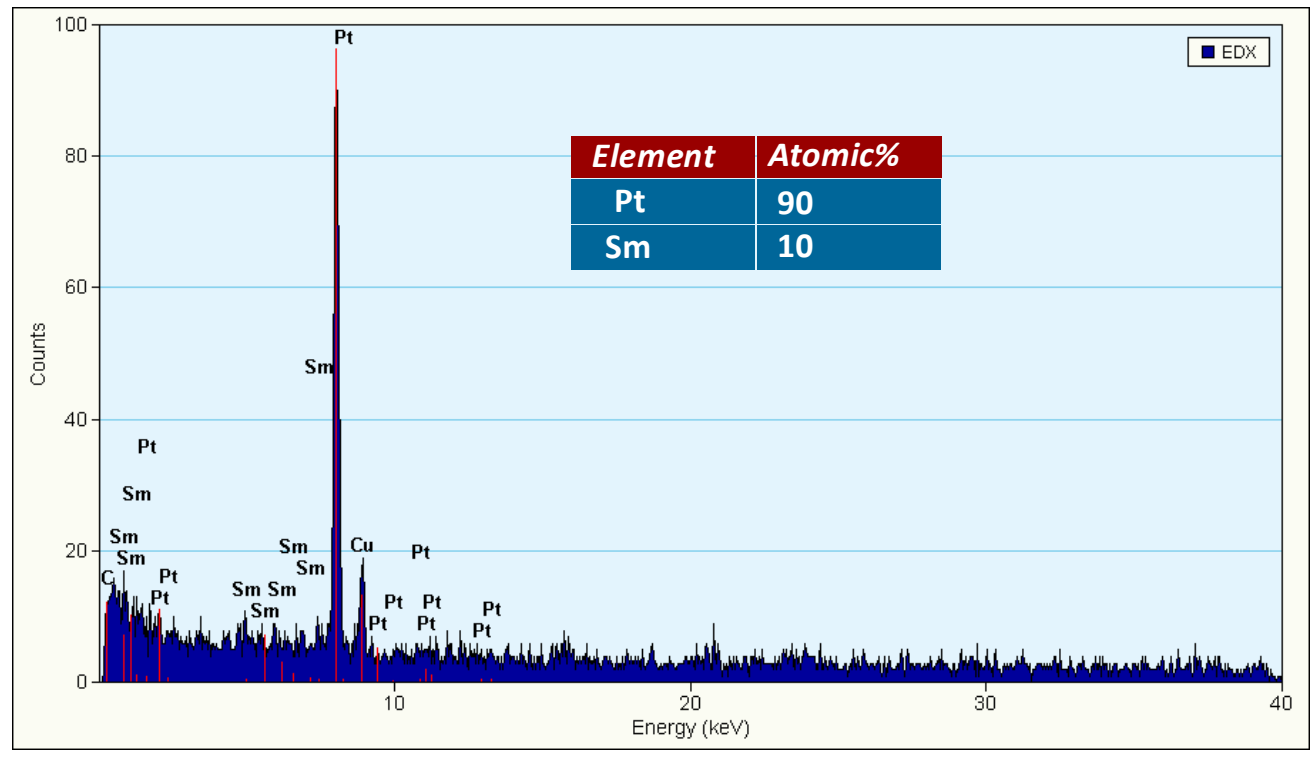

Figure S2. EDX spectrum of concave cubic Pt-Sm alloy NCs. 


\section{ICP-MS Analysis.}

Table S2. ICP-MS results of concave cubic Pt and Pt-Sm alloy NCs.

\begin{tabular}{|l|l|l|}
\hline Electrocatalyst & Element & Content $/ \mu \mathrm{g}$ \\
\hline Concave cubic Pt NCs ${ }^{\mathrm{a}}$ & $\mathrm{Pt}$ & 0.962 \\
\hline \multirow{2}{*}{ Concave cubic Pt-Sm alloy NCs ${ }^{\mathrm{b}}$} & $\mathrm{Pt}$ & 0.946 \\
\cline { 2 - 3 } & $\mathrm{Sm}$ & 0.068 \\
\hline
\end{tabular}

a The sample prepared by using mixed precursors with Pt/Sm molar ratios of 100:0.

$\mathrm{b}$ The sample prepared by using mixed precursors with Pt/Sm molar ratios of 91:9.

ICP-MS result indicates that the atom ratio of $\mathrm{Pt}$ to $\mathrm{Sm}$ in concave cubic Pt-Sm alloy NCs is 91.5 to 8.5 , which is close to that of the precursors (91:9) in the plating solution. 


\section{Electrocatalytic Measurements.}

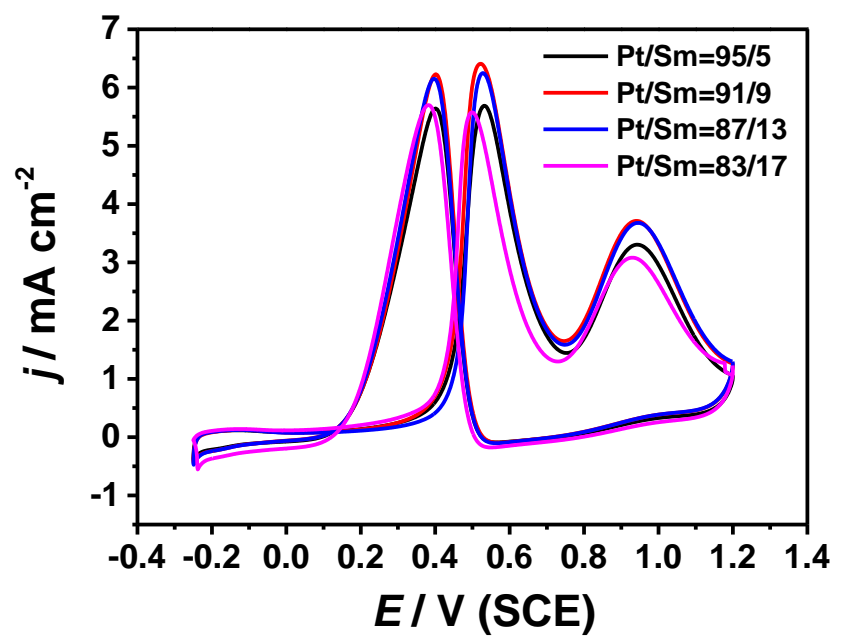

Figure S3. Cyclic voltammograms of ethanol oxidation on samples obtained by using mixed precursors with Pt/Sm molar ratios of 95:5, 91:9, 87:13 and 83:17 in 0.1 M ethanol + 0.1 $\mathrm{M} \mathrm{HClO}_{4}$. Scan rate: $50 \mathrm{mV} \mathrm{s}^{-1}$.

As can been see from Figure S3, the optimal composition of concave cubic Pt-Sm alloy NCs for electrocatalytic ethanol oxidation was determined as sample obtained by using the mixed precursor with Pt/Sm molar ratio of 91:9.

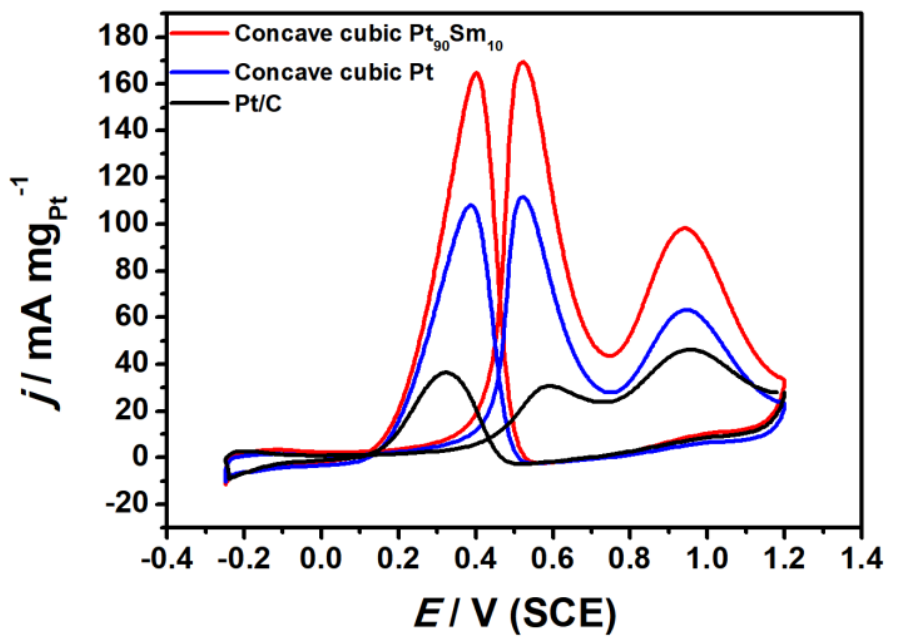


Figure S4. Cyclic voltammograms of ethanol oxidation of concave cubic Pt90Sm10 alloy NCs, concave cubic Pt NCs and Pt/C catalyst in $0.1 \mathrm{M}$ ethanol + $0.1 \mathrm{M} \mathrm{HClO}_{4}$. Scan rate: $50 \mathrm{mV} \mathrm{s}^{-1}$.

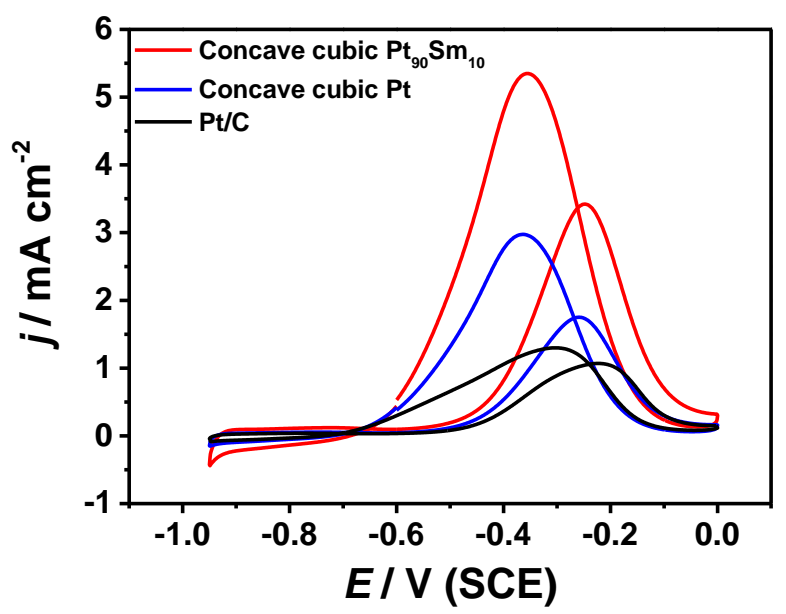

Figure S5. Cyclic voltammograms of ethanol oxidation of concave cubic Pt90Sm10 alloy NCs, concave cubic Pt NCs and Pt/C catalyst in $0.1 \mathrm{M}$ ethanol + 0.1 M NaOH. Scan rate: $50 \mathrm{mV} \mathrm{s}^{-1}$. 


\section{Computational Methods.}

The bottom two layer atoms were fixed in the slab while the top two layers atoms were relaxed during all the optimization process. The vacuum region layers were built more than $12 \AA$ to eliminate the slab interaction in z direction. The adsorption energy was defined as: $E_{\text {ad }}=E(\operatorname{ad} / \operatorname{surf})-$ $E(\mathrm{ad})-E($ surf $)$, where $E(\mathrm{ad} / \mathrm{surf}), E(\mathrm{ad})$, and $E(\mathrm{surf})$ are the total energies of the adsorbate binding to Pt surface, free adsorbate in gas phase and clean Pt, respectively. The free energy of species was obtained from $G=E+$ ZPE - TS, where $E$ is the total energy of species, $S$ is the entropy and ZPE is the zero point energy at room temperature $(300 \mathrm{~K})$. The reaction free energy of $\mathrm{AH} \rightarrow \mathrm{A}^{+} \mathrm{H}^{+}+\mathrm{e}^{-}$ was calculated as $\Delta G=G(\mathrm{~A})+G\left(\mathrm{H}^{+}+\mathrm{e}^{-}\right)-G(\mathrm{AH})$. At the electrode potential of $0 \mathrm{~V}, \mathrm{pH}=0\left(\left[\mathrm{H}^{+}\right]=\right.$ $1 \mathrm{M}$ ), at $298 \mathrm{~K}$, due to the equilibrium of $\mathrm{H}^{+}+\mathrm{e}^{-} \rightarrow 1 / 2 \mathrm{H}_{2}$, we can use the free energy of $1 / 2 \mathrm{H}_{2}$ in the gas phase to replace that of $\mathrm{H}^{+}+\mathrm{e}^{-} .{ }^{\mathrm{S} 1} \mathrm{All}$ the vibrational frequencies, $v_{i}(\mathrm{~Hz})$, were calculated based on the harmonic oscillators approximation. ${ }^{\mathrm{S} 2}$

Two exposed surface Pt sites on $\mathrm{Pt}_{3} \mathrm{Sm}(310)$ were identified as shown in Figure $\mathrm{S} 1$ (denoted as A and $\mathrm{B})$. The reaction mechanism on these two sites was both examined and the reaction energies and kinetic data were listed in Table $\mathrm{S} 1$. One can see that the rate determining barriers $\left(\mathrm{CH}_{3} \mathrm{CHOH}^{*} \rightarrow\right.$ $\mathrm{CH}_{3} \mathrm{COH}^{*}$ ) on site $\mathrm{A}$ is $0.60 \mathrm{eV}$ lower than $0.67 \mathrm{eV}$ on site $\mathrm{B}$, suggestive of a higher catalytic activity provided by site A. The free energy profiles and optimized structures were shown in Figure S2.

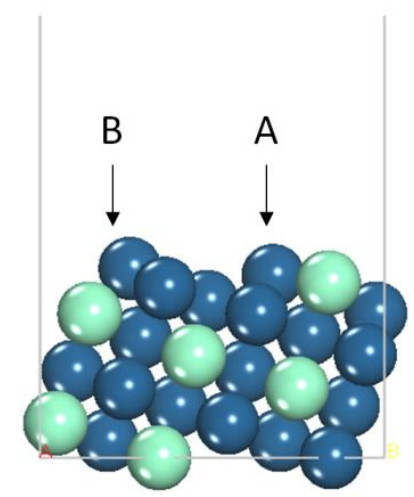


Figure S6.Side view of the model of $\mathrm{Pt}_{90} \mathrm{Sm}_{10}(310)$ with site A and B. Blue: Pt; green: Sm.

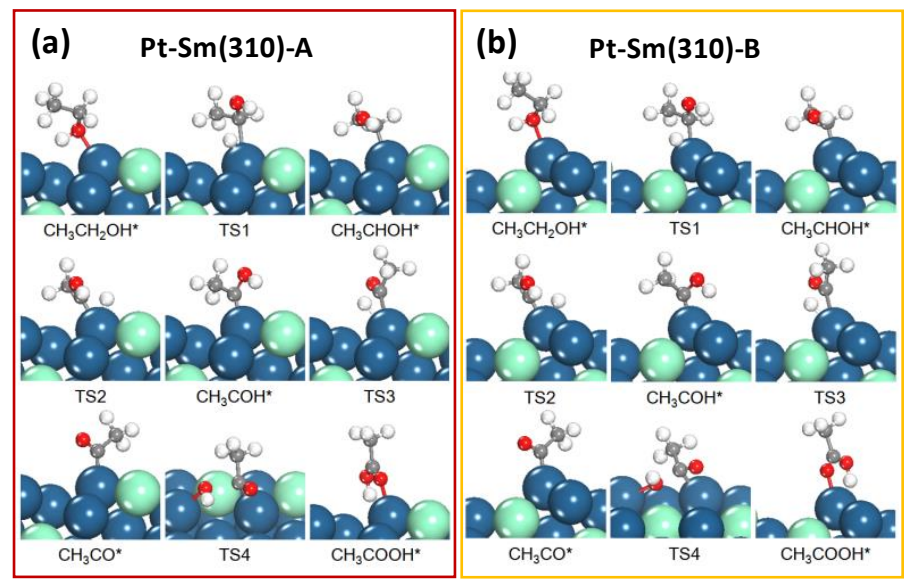

Figure S7. Optimized intermediates and transition states in ethanol electrooxiation on $\mathrm{Pt}_{3} \mathrm{Sm}(310)-\mathrm{A}$ and B. Blue: Pt; green: Sm; grey: C; hydrogen: H; red: O.

Table S3. Calculated activation energies $\left(E_{a}\right)$ and reaction energies $(\Delta G)$ in eV of elementary steps on different surfaces respectively.

\begin{tabular}{|c|c|c|c|c|c|c|}
\hline \multirow{2}{*}{ Surface reactions } & \multicolumn{2}{|c|}{$\mathrm{Pt}(310)$} & \multicolumn{2}{c|}{$\mathrm{PtSm}(310)-\mathrm{A}$} & \multicolumn{2}{c|}{$\mathrm{PtSm}(310)-\mathrm{B}$} \\
\hline & $\mathrm{E}_{\mathrm{a}}$ & $\Delta \mathrm{G}$ & $\mathrm{E} a$ & $\Delta \mathrm{G}$ & $\mathrm{E}_{\mathrm{a}}$ & $\Delta \mathrm{G}$ \\
\hline $\mathrm{CH}_{3} \mathrm{CH}_{2} \mathrm{OH} \rightarrow \mathrm{CH}_{3} \mathrm{CH}_{2} \mathrm{OH}^{*}$ & $/$ & -0.11 & $/$ & 0.01 & $/$ & 0.26 \\
\hline $\mathrm{CH}_{3} \mathrm{CH}_{2} \mathrm{OH}^{*} \rightarrow \mathrm{CH}_{3} \mathrm{CHOH}^{*}$ & 0.54 & -0.05 & 0.41 & -0.09 & 0.35 & -0.22 \\
\hline $\mathrm{CH}_{3} \mathrm{CHOH}^{*} \rightarrow \mathrm{CH}_{3} \mathrm{COH}^{*}$ & 0.50 & -0.25 & 0.60 & 0.03 & 0.67 & 0.02 \\
\hline $\mathrm{CH}_{3} \mathrm{COH}^{*} \rightarrow \mathrm{CH}_{3} \mathrm{CO}^{*}$ & 0.16 & -0.15 & 0.17 & 0.04 & 0.13 & -0.32 \\
\hline $\mathrm{CH}_{3} \mathrm{CO}^{*}+\mathrm{H}_{2} \mathrm{O} \rightarrow \mathrm{CH}_{3} \mathrm{COOH}^{*}$ & 1.21 & 0.09 & 0.42 & -0.34 & 0.61 & -0.04 \\
\hline $\mathrm{CH}_{3} \mathrm{COOH}^{*} \rightarrow \mathrm{CH}_{3} \mathrm{COOH}^{*}$ & $/$ & -0.05 & $/$ & -0.17 & $/$ & -0.22 \\
\hline
\end{tabular}




\section{References}

(S1) Norskov, J. K.; Rossmeisl, J.; Logadottir, A.; Lindqvist, L.; Kitchin, J. R.; Bligaard, T.; Jonsson, H. Origin of the overpotential for oxygen reduction at a fuel-cell cathode. J. Phys. Chem. B, 2004, $108,17886-17892$.

(S2) Gokhale, A. A.; Kandoi, S.; Greeley, J. P.; Mavrikakis, M.; Dumesic, J. A. Molecular-level descriptions of surface chemistry in kinetic models using density functional theory. Chem. Eng. Sci., 2004, 59, 4679-4691. 